\title{
EXISTENCE RESULT OF POSITIVE SOLUTION FOR BOUNDARY VALUE PROBLEMS OF FRACTIONAL ORDER WITH INTEGRO-DIFFERENTIAL BOUNDARY CONDITIONS
}

\section{YousEF GHOLAMI}

Abstract. In this paper we study the following fractional boundary value problem with integrodifferential boundary conditions

$$
\left\{\begin{array}{l}
D_{0^{+}}^{\alpha} u(t)-f\left(t, u(t), D_{0^{+}}^{\alpha-1} u(t), D_{0^{+}}^{1-\alpha} u(t)\right)=0, t \in[0, T], n-1 \leqslant \alpha<n, \\
u^{(j)}(0)=0, D_{0^{+}}^{\alpha-1} u(T)+\int_{0}^{T} u(\omega) d \omega+\sum_{i=1}^{m-2} \beta_{i} u\left(\xi_{i}\right)=0, j=0, \ldots, n-2, \\
0<\xi_{i}<\xi_{i+1}<T, \beta_{i} \in[0, \infty), i=1,2, \ldots, m-2, n \in \mathbb{N} \backslash\{1\}, T>0,
\end{array}\right.
$$

where $D_{0^{+}}^{\alpha}, D_{0^{+}}^{\alpha-1}$ represent the standard Riemann-Liouville fractional derivative of order $\alpha$. The main result includes some interesting fixed point and functional analysis techniques to obtain claimed existence result.

Mathematics subject classification (2010): fractional derivative, generalized boundary conditions, positive solutions, fixed point theory.

Keywords and phrases: 34A08, 34B18, 47H10.

\section{REFERENCES}

[1] B. Ahmad, S.K. NTOUYAS, Nonlinear fractional differential equations and inclusions of arbitrary order and multi-strip boundary conditions, Electronic Journal of Differential Equations, 98, Vol. 2012 (2012), 1-22.

[2] A. CABADA, G. WANG, Positive solutions of nonlinear fractional differential equations with integral boundary value conditions, Journal of Mathematical Analysis and Applications, 389, (2012), 403-411.

[3] K. GHAnbari, Y. Gholami, Existence and multiplicity of positive solutions for m-point nonlinear fractional differential equations on the half line, Electronic Journal of Differential Equations, 238, Vol. 2012 (2012), 1-15.

[4] K. Ghanbari, Y. Gholami, Existence and nonexistence results of positive solution for nonlinear fractional eigenvalue problem, Journal of Fractional Calculus and Applications, 2, Vol. 4. Jan. 2013, $1-12$.

[5] K. Ghanbari, Y. Gholami, H. Mirzaei, Existence and multiplicity results of positive solutions for boundary value problems of nonlinear fractional differential equations , Dynamics of Continuous, Discrete and Impulsive Systems Series A: Mathematical Analysis, 20, (2013), 543-558.

[6] L.P. Lebedev, I.I. Vorovich, G.M.L. Gladwell, Functional Analysis (Applications in Mechanics and Inverse Problems, $2^{\text {end }}$ Edition), Kluwer Academic Publishers, 2002.

[7] A.A. Kilbas, H.M. SRivastava, J.J. Trujillo, Theory and Applications of fractional Differential Equations, North-Holland mathematics studies,Elsvier science, 204, (2006).

[8] N. Kosmatov, Solutions to a class of nonlinear differential equations of fractional order, Electronic Journal of Qualitative Theory of Differential Equations, 20, (2009), 1-13. 
[9] S.K. NTOUYAS, Boundary value problems for nonlinear fractional differential equations and inclusions with nonlocal and fractional integral boundary conditions, Opuscula Math, 33, (2013), 117-138.

[10] I. Poudlobny, Fractional Differential Equations, Mathematics in Science and Applications, Academic Press, 19 (1999).

[11] G. WAng, S. LiU, T.P. AgARWAL, L. ZhAng, Positive solutions of integral boundary value problem involving Riemann-Liouville fractional derivative, Journal of Fractional Calculus and Applications, 4 (2) (2013), 312-321.

[12] S. Zhang, Positive solutions for boundary value problem of nonlinear fractional differential equations, Ellectronic Journal of Differential Equations, 36, Vol. 2006(2006), 1-12.

[13] X. SU, S. ZHANG, Unbounded solutions to a boundary value problem of fractional order on the half-line, Computers and Mathematics with Applications, 61 (2011), 1079-1087.

[14] X. ZHAO, W. GE, Unbounded solutions for a fractional boundary value problem on the infinite interval, Acta Appl Math, 109 (2010), 495-505.

[15] W. ZHONG, W. Lin, Nonlocal and multiple-point boundary value problem for fractional differential equations, Comput. Math. Appl, 39 (2010), 1345-1351. 